ASTHMA

\title{
Wheeze, asthma diagnosis and medication use: a national adult survey in a developing country
}

\author{
R I Ehrlich, N White, R Norman, R Laubscher, K Steyn, C Lombard, D Bradshaw
}

Thorax 2005;60:895-901. doi: 10.1136/thx.2004.030932

See end of article for authors' affiliations .....................

Correspondence to: Professor R I Ehrlich, School of Public Health and Family Medicine, Faculty of Health Sciences, University of Cape Town, Observatory 7925, South Africa; ehrlich@cormack. uct.ac.za

Received 8 July 2004 Accepted 6 May 2005

\begin{abstract}
Background: As relatively little is known about adult wheeze and asthma in developing countries, this study aimed to determine the predictors of wheeze, asthma diagnosis, and current treatment in a national survey of South African adults.

Methods: A stratified national probability sample of households was drawn and all adults (>14 years) in the selected households were interviewed. Outcomes of interest were recent wheeze, asthma diagnosis, and current use of asthma medication. Predictors of interest were sex, age, household asset index, education, racial group, urban residence, medical insurance, domestic exposure to smoky fuels, occupational exposure, smoking, body mass index, and past tuberculosis.

Results: A total of 5671 men and 8155 women were studied. Although recent wheeze was reported by $14.4 \%$ of men and $17.6 \%$ of women and asthma diagnosis by $3.7 \%$ of men and $3.8 \%$ of women, women were less likely than men to be on current treatment (OR 0.6 ; $95 \%$ confidence interval (CI) 0.5 to 0.8 ). A history of tuberculosis was an independent predictor of both recent wheeze (OR 3.4; $95 \% \mathrm{Cl} 2.5$ to 4.7 ) and asthma diagnosis (OR 2.2; $95 \% \mathrm{Cl} 1.5$ to 3.2), as was occupational exposure (wheeze: OR 1.8; $95 \%$ $\mathrm{Cl} 1.5$ to 2.0 ; asthma diagnosis: $\mathrm{OR} 1.9 ; 95 \% \mathrm{Cl} 1.4$ to 2.4 ). Smoking was associated with wheeze but not asthma diagnosis. Obesity showed an association with wheeze only in younger women. Both wheeze and asthma diagnosis were more prevalent in those with less education but had no association with the asset index. Independently, having medical insurance was associated with a higher prevalence of diagnosis. Conclusions: Some of the findings may be to due to reporting bias and heterogeneity of the categories wheeze and asthma diagnosis, which may overlap with post tuberculous airways obstruction and chronic obstructive pulmonary disease due to smoking and occupational exposures. The results underline the importance of controlling tuberculosis and occupational exposures as well as smoking in reducing chronic respiratory morbidity. Validation of the asthma questionnaire in this setting and research into the pathophysiology of post tuberculous airways obstruction are also needed.
\end{abstract}

S tandardised population surveys of asthma in adults have produced valuable information about the comparative prevalence and determinants of asthma in developed countries. ${ }^{12}$ However, relatively few such studies have been carried out in developing countries. Recent examples include reports from India, ${ }^{3}$ Algeria, ${ }_{1}$ Albania, ${ }^{4}$ China, ${ }^{5}$ and Turkey. ${ }^{6}$ More such investigations are needed, especially as disparate patterns of urbanisation, infectious disease burden, and medical care may result in risk factor profiles, competing causes of ill health, and types of wheezing illness different from those of developed countries.

South Africa is a middle income country characterised by a relatively high degree of industrialisation, a sizeable affluent class, and large scale urban poverty and rural underdevelopment. Primary commodity mining remains an important part of the industrial base. The country has a per capita GDP of US\$8900 (1999 purchasing power), placing it alongside countries such as Brazil and Mexico. It suffers a quadruple disease burden characterised by high rates of HIV infection, other infectious disease, chronic non-communicable disease, and injury.

A 1998 national health survey including an adult health module provided the opportunity to examine the prevalence and determinants of wheezing symptoms, asthma diagnosis, and use of asthma medication among adults. Chronic bronchitis has been considered in a companion paper. ${ }^{8}$

\section{METHODS}

The South African Demographic and Health Survey was a household survey designed to provide cross sectional data on a nationally representative sample of the non-institutionalised South African population. ${ }^{9}$ The sample included people from all settings including informal settlements and remote rural areas, but excluding employer provided hostel accommodation. A two stage sample was drawn using the 1996 population census as a sample frame. The first stage selected census enumeration areas with the probability of selection proportional to the number of "visiting points" in the enumeration area, stratified into urban and non-urban ("rural") areas in each of the nine provinces of South Africa. The second stage involved a systematic random sample of five visiting points in the selected urban enumeration areas and 10 visiting points in the rural areas. Certain strata were overrepresented in the sample to allow sufficient precision for provincial and racial group estimates. *

Two linked surveys were conducted-a women's health survey and a general adult survey. The latter survey provided the data analysed in this report. All adults (>14 years of age) who were residents of every second visiting point were included. There was no proxy reporting. The questionnaires

\footnotetext{
*Apartheid sought to categorise all South Africans into one of four racial groups: Asian (or Indian) (2.6\% of the population, 1996 census), African (or black) $(76.7 \%)$, coloured $(8.9 \%)$, and white $(10.9 \%)$. The social stratification by racial group reflects large and enduring historical disparities in socioeconomic status, quality of housing and services and access to medical care, and consequently in disease risk. Racial group stratification has been retained in national health surveillance in South Africa to reflect a social complexity not fully captured by education, income, etc and to monitor progress toward reduction of health disparities.
} 
were prepared in all 11 official South African languages and checked by back translation. Interviewers were trained over several weeks. Interviews took place also after working hours, and interviewers were instructed to return on two further occasions if the desired respondent was not found at home.

Two questionnaires of relevance to this study were used. (1) A household questionnaire characterised all household members including their age, sex, racial group (self classified) and education, and elicited features of the dwelling such as fuel use, services used, and goods owned. A household asset index was developed using principal component factor analysis on the living conditions and household assets information. ${ }^{10}{ }^{11}$ The analysis identified 10 household characteristics for combination in the first factor-for example, having electricity, water and flush toilets and certain durable goods, and reporting that nobody in the household ever went hungry. Households were categorised into quintiles on the asset index scale. (2) An adult health questionnaire elicited information about medical history, symptoms of disease and utilisation of health services, as well as the occupational history and smoking habits of the respondent. All medications used daily for the previous month and shown to the interviewer were recorded and subsequently classified.

Height was recorded using a metal measuring tape secured against a wall or nearest flat vertical surface with a flat headboard, and weight was measured to the nearest $0.5 \mathrm{~kg}$ with the subject wearing only light clothing and no shoes using a calibrated bathroom scale (Soehnle, Nasau, Germany). Peak expiratory flow rate (PEFR) was recorded using a Tru-Zone mini-peak flow meter (Trudell Medical International, Canada). Fieldworkers underwent intensive training and were monitored during the study by supervisors.

\section{Respiratory outcomes}

Respiratory outcomes included two primary asthma symptoms: wheeze in the past 12 months ("recent wheeze") (with additional questions covering wheeze with breathlessness and wheeze only with a cold) and sleep disturbance by wheeze (see Appendix 1). The wording was similar to, but not identical with, that used in the European Community Respiratory Health Survey (ECRHS). ${ }^{3}$ Asthma diagnosis was based on having ever been given the diagnosis by a doctor or nurse. Current asthma treatment was defined as positive if one or more asthma medications (inhaled or oral bronchodilators or glucocorticosteroids) used daily by the study participant for the last month was shown to the interviewer.

\section{Analysis of data}

In order to derive a predictive model, all of the variables of interest were included in a logistic regression model to estimate prevalence odds ratios and 95\% confidence intervals (CI). The model included sociodemographic variables (sex, age, asset index, education, racial group, urban versus rural residence), exposure variables (smoking status, occupational exposure, smoky domestic fuel exposure), and "medical" variables (history of previous tuberculosis and body mass index) (see Appendix 1 for definitions). Body mass index was included because of suggestive literature on its association with asthma. ${ }^{12-14}$ Wald tests were performed to assess the significance of the predictor variables in the logistic regression models. These were complemented by $t$ tests for the significance of the stratum coefficients of each variable compared with their reference stratum. For each variable the estimated model coefficients and their $95 \%$ confidence limits were converted into odds ratios. In addition, tree regression modelling ${ }^{15}$ of wheeze and asthma diagnosis was carried out on the same set of predictors to determine their importance in the analysis. Tree regression and, specifically, classification trees in the context of the outcomes of this paper constitute a structured modelling approach that uses a stepwise process of recursive partitioning to reveal underlying relationships in the data. It helps to identify optimal categorisation of variables and explores possible effect modification.

The denominator used to examine predictors of current asthma medication use included only respondents with wheezing in the past 12 months and/or those who had ever had a diagnosis of asthma. To take into account the complex survey design, the survey set option in the STATA statistical package (STATA Release 7.0) was used for the stratified and cluster design. The data were weighted to obtain nationally representative estimates of both counts and prevalences.

The validity of the respiratory outcomes was examined by analysing their respective associations with PEFR. A reference prediction equation, including age, height and weight as predictors, was derived from the survey data on a subsample of 2373 men and 5080 women which excluded smokers, pregnant women, and those who had reported lung disease. ${ }^{9}$ PEFR was expressed as a percentage of predicted. The differences between groups in mean PEFR and mean percentage predicted PEFR were examined using a $t$ test. Population attributable fractions $(\mathrm{PAFs})^{16}$ in respect of selected variables were calculated for recent wheeze and asthma diagnosis.

Ethical approval for the study was obtained from the ethical committee of the South African Medical Research Council. Informed consent was sought from each study respondent.

\section{RESULTS}

A total of 5771 men and 8155 women participated in the study. The difference between the sexes was due to more women being sampled and a higher response rate by women than by men ( $92 \% v 86 \%)$.

The associations of recent wheeze and asthma diagnosis with PEFR are summarised in table 1. Subjects with recent wheeze or an asthma diagnosis had a significantly lower mean PEFR and PEFR as a percentage of predicted than those without.

The unadjusted associations of the various predictor variables with recent wheeze are shown in table 2. As the findings for wheezing with breathlessness, wheezing not only with a cold, and night wheeze were very similar to those for recent wheeze, only the results for recent wheeze are presented in these tables and in further analyses. Predictors of recent wheeze in univariate analysis were sex (women $17.5 \%$, men $14.4 \%$ ), increasing age, racial group (whites and Asians had a higher prevalence than the other groups), rural residence, use of smoky domestic fuel, occupational exposures, smoking, a past history of tuberculosis, and both obesity and being underweight. Increased education and (for some strata) higher asset index were protective factors.

After adjustment (table 3), the effect of age on recent wheeze was attenuated while asset index was not a significant contributor to the overall model (Wald test). The female excess was strengthened. Of the environmental exposures, occupational exposures and smoking but not domestic fuel remained predictive of recent wheeze. A past history of tuberculosis remained positively associated with wheeze, while obesity continued to have a weak effect. There was a strong monotonic trend to a decrease in the prevalence of recent wheeze with a higher education level.

The unadjusted associations of the predictor variables with an asthma diagnosis are shown in table 2. Significant predictors were age $>44$ years, being in the highest asset index group, possession of medical insurance, past tuberculosis, occupational exposures, and smoking. Africans were less likely to report a diagnosis than other groups, as were 


\begin{tabular}{|c|c|c|c|c|}
\hline & $\mathbf{N}^{*}$ & PEFR (I/min) & Mean & $\begin{array}{l}\text { Difference } \\
\text { (No-yes) }(95 \% \mathrm{Cl})^{* *}\end{array}$ \\
\hline \multicolumn{5}{|c|}{ Recent wheeze } \\
\hline \multicolumn{5}{|c|}{ Men } \\
\hline No & 4857 & $\begin{array}{l}\text { Mean } \\
\% \text { predicted }\end{array}$ & $\begin{array}{l}374 \\
105\end{array}$ & \\
\hline Yes & 814 & $\begin{array}{l}\text { Mean } \\
\% \text { predicted }\end{array}$ & $\begin{array}{r}335 \\
97\end{array}$ & $\begin{array}{l}39(28 \text { to } 51) \\
8(4 \text { to } 11)\end{array}$ \\
\hline \multicolumn{5}{|c|}{ Women } \\
\hline No & 6718 & $\begin{array}{l}\text { Mean } \\
\% \text { predicted }\end{array}$ & $\begin{array}{l}308 \\
104\end{array}$ & \\
\hline Yes & 1437 & $\begin{array}{l}\text { Mean } \\
\% \text { predicted }\end{array}$ & $\begin{array}{r}274 \\
96\end{array}$ & $\begin{array}{l}34(26 \text { to } 41) \\
8(6 \text { to } 11)\end{array}$ \\
\hline \multicolumn{5}{|c|}{ Asthma diagnosis } \\
\hline \multicolumn{5}{|c|}{ Men } \\
\hline No & 5460 & $\begin{array}{l}\text { Mean } \\
\% \text { predicted }\end{array}$ & $\begin{array}{l}370 \\
104\end{array}$ & \\
\hline Yes & 211 & $\begin{array}{l}\text { Mean } \\
\% \text { predicted }\end{array}$ & $\begin{array}{r}337 \\
95\end{array}$ & $\begin{array}{l}33(5 \text { to } 61) \\
9(2 \text { to } 16)\end{array}$ \\
\hline \multicolumn{5}{|c|}{ Women } \\
\hline No & 7843 & $\begin{array}{l}\text { Mean } \\
\% \text { predicted }\end{array}$ & $\begin{array}{l}304 \\
103\end{array}$ & \\
\hline Yes & 312 & $\begin{array}{l}\text { Mean } \\
\% \text { predicted }\end{array}$ & $\begin{array}{r}269 \\
93\end{array}$ & $\begin{array}{l}35(20 \text { to } 50) \\
11(6 \text { to } 15)\end{array}$ \\
\hline
\end{tabular}

respondents using smoky domestic fuels. After adjustment (table 3) and in contrast to recent wheeze, asthma diagnosis showed no association with age, sex or smoking. The trend to a lower prevalence of asthma diagnosis among Africans than in other groups persisted, but racial group was not a significant contributor to the model. Past tuberculosis, occupational exposures, and possession of medical insurance remained significant predictors of an asthma diagnosis after adjustment. Education showed a less clearcut protective effect than for recent wheeze.

Of all participants, $1.9 \%$ of men and $1.6 \%$ of women reported regular current use of asthma medication. Predictors of asthma medication use were examined in the subgroup with wheeze in the past 12 months and/or a diagnosis of asthma $(n=2434)$. Within this subgroup the prevalence of current asthma medication use was $11.2 \%$ among men and $7.2 \%$ among women. In univariate analysis (table 2 ), asthma medication use was positively associated with male sex, age $>44$ years, asset index, possession of medical insurance, use of non-smoky fuels, occupational exposures, and heavy daily smoking. Africans were significantly less likely to report asthma medication use than other racial groups. After adjustment (table 3), a number of these associations with asthma medication use were no longer significant. However, men were still significantly more likely than women to use asthma medication, as were older respondents and those using non-smoky fuels in the home compared with those using smoky fuels. A positive but non-significant trend between asset index and treatment was evident, while Africans remained less likely to be on treatment than other groups (although the difference from whites was now nonsignificant).

Since domestic fuel was included in the definition of the asset index, all of the models were rerun without domestic fuel use. The only notable change was that the association of medication use with the asset index became even stronger. For example, the odds ratio for the highest versus the lowest stratum increased to 3.6 (95\% CI 1.3 to 9.9 ).

Tree regression analysis suggested effect modification by age. The influence of age was further examined by stratifying the models using $>44$ years as the cut off point. The only notable changes were for recent wheeze. Ex-smoking (OR $2.5,95 \%$ CI 1.1 to 5.9 ) and obesity (OR $1.3,95 \%$ CI 1.1 to 1.6 ) were predictors of recent wheeze only in the younger age group, while being underweight emerged as a predictor in the older age group (OR 1.6, 95\% CI 1.1 to 2.2 ). In the younger group the positive association of recent wheeze with obesity was evident only among women (OR 1.6, 95\% CI 1.2 to 2.0 ), while in men there was an inverse association (OR 0.5, 95\% CI 0.3 to 0.9 ). Finally, the association with a history of tuberculosis was stronger in younger subjects (OR 4.7, 95\% CI 3.3 to 6.8 ) than in older subjects (OR 2.3, 95\% CI 1.5 to 3.6).

\section{Attributable fractions}

For illustrative purposes, the contribution to the burden of wheezing of four modifiable factors (past tuberculosis, occupational exposure, smoking and obesity) were estimated (table 4). Interpretation is based on the assumption of causation. The PAF of occupational exposure was $12.2 \%$ for recent wheeze and $13.6 \%$ for asthma diagnosis.

\section{DISCUSSION}

This is the first nationally representative survey of wheeze and asthma diagnosis among adults in South Africa, and possibly the first ever such study in a developing country.

The sampling produced a female to male ratio of 1.4, partly due to a higher response rate among women but mainly due to undersampling of men. Since the interviews required finding an adult respondent at home, there is likely to have been underrepresentation of working people, particularly men working overtime or shifts or who were away from home. Male worker hostels, which are a common form of housing for African migrant workers in mining and certain other industries, were not surveyed. The net effect of these selection factors may have been that employed low income men were underrepresented in the survey. This may have introduced an upward bias in prevalence, in that men found at home may be more likely to have had a diagnosis or to be on treatment than men unavailable for interviewing. 
Table 2 Recent wheeze, asthma diagnosis, and medication use by sociodemographic, exposure and medical characteristics (univariate analysis)

\begin{tabular}{|c|c|c|c|c|c|c|c|c|}
\hline \multirow[b]{2}{*}{ Variable } & \multirow[b]{2}{*}{$\mathbf{N}$} & \multicolumn{2}{|c|}{ Recent wheeze } & \multicolumn{2}{|c|}{ Asthma diagnosis } & \multicolumn{3}{|c|}{ Asthma medication use } \\
\hline & & $\%$ & OR $(95 \% \mathrm{Cl})$ & $\%$ & OR $(95 \% \mathrm{Cl})$ & $\mathrm{N}$ & $\%$ & OR $(95 \% \mathrm{Cl})$ \\
\hline Overall & 13826 & 16.3 & - & 3.8 & - & 2434 & 8.6 & - \\
\hline \multicolumn{9}{|l|}{ Sex } \\
\hline Men & 5671 & 14.4 & 1.0 & 3.7 & 1.0 & 892 & 11.2 & 1.0 \\
\hline Women & 8155 & 17.6 & $1.3(1.1 \text { to } 1.4)^{*}$ & 3.8 & 1.0 (0.8 to 1.3$)$ & 1542 & 7.2 & $0.6(0.5 \text { to } 0.8)^{*}$ \\
\hline \multicolumn{9}{|l|}{ Age (years) } \\
\hline $15-19$ & 2128 & 11.3 & 1.0 & 3.1 & 1.0 & 272 & 5.2 & 1.0 \\
\hline $20-44$ & 7080 & 13.4 & $1.2(1.0 \text { to } 1.5)^{*}$ & 2.9 & $1.0(0.7$ to 1.3$)$ & 1027 & 6.5 & $1.3(0.6$ to 2.7$)$ \\
\hline$>44$ & 4617 & 23.1 & $2.3(1.9 \text { to } 2.9)^{*}$ & 5.4 & $1.8(1.3 \text { to } 2.6)^{*}$ & 1135 & 11.4 & $2.3(1.1 \text { to } 5.1)^{*}$ \\
\hline \multicolumn{9}{|l|}{ Asset index } \\
\hline I (poorest) & 1749 & 20.3 & 1.0 & 3.7 & 1.0 & 378 & 3.2 & 1.0 \\
\hline II & 2776 & 17.7 & $0.8(0.7$ to 1.0$)$ & 2.9 & $0.8(0.5$ to 1.2$)$ & 513 & 6.1 & $2.0(1.1 \text { to } 3.9)^{*}$ \\
\hline III & 2781 & 12.9 & $0.6(0.5 \text { to } 0.7)^{*}$ & 2.5 & $0.7(0.4$ to 1.1$)$ & 384 & 6.0 & $1.9(0.9$ to 3.9$)$ \\
\hline IV & 3241 & 14.8 & $0.7(0.6 \text { to } 0.8)^{*}$ & 3.7 & $1.0(0.7$ to 1.5$)$ & 517 & 10.1 & $3.4(1.8 \text { to } 6.5)^{*}$ \\
\hline $\mathrm{V}$ & 3280 & 17.3 & $0.8(0.6$ to 1.0$)$ & 5.7 & $1.6(1.1 \text { to } 2.3)^{*}$ & 642 & 14.2 & $5.0(2.5 \text { to } 10.1)^{*}$ \\
\hline \multicolumn{9}{|l|}{ Education (years) } \\
\hline None & 1747 & 26.0 & 1.0 & 4.5 & 1.0 & 472 & 6.1 & 1.0 \\
\hline $1-7$ & 3755 & 18.6 & $0.6(0.6 \text { to } 0.8)^{*}$ & 4.5 & $1.0(0.7$ to 1.4$)$ & 750 & 9.7 & 1.7 (1.0 to 2.8 ) \\
\hline $8-12$ & 7311 & 13.3 & $0.4(0.4 \text { to } 0.5)^{*}$ & 3.1 & $0.7(0.5 \text { to } 0.9)^{*}$ & 1063 & 8.8 & $1.5(0.8$ to 2.8$)$ \\
\hline$>12$ & 935 & 12.0 & $0.4(0.3 \text { to } 0.5)^{*}$ & 5.2 & $1.2(0.8$ to 1.8$)$ & 138 & 8.8 & $1.5(0.7$ to 3.1$)$ \\
\hline \multicolumn{9}{|l|}{ Racial group } \\
\hline African & 10525 & 15.6 & 1.0 & 3.0 & 1.0 & 1739 & 5.8 & 1.0 \\
\hline Coloured & 1444 & 14.3 & $0.9(0.7$ to 1.1$)$ & 4.7 & $1.6(1.2 \text { to } 2.3)^{*}$ & 229 & 19.1 & $3.8(2.3 \text { to } 6.4)^{*}$ \\
\hline White & 1331 & 23.2 & $1.6(1.2 \text { to } 2.3)^{*}$ & 8.6 & $3.1(2.1 \text { to } 4.4)^{*}$ & 358 & 13.1 & $2.5(1.2 \text { to } 5.2)^{*}$ \\
\hline Asian & 495 & 18.8 & $1.3(1.0 \text { to } 1.7)^{*}$ & 5.9 & $2.1(1.3 \text { to } 3.3)^{*}$ & 101 & 18.4 & $3.7(2.0 \text { to } 6.7)^{*}$ \\
\hline \multicolumn{9}{|l|}{ Residence } \\
\hline Urban & 8567 & 15.3 & 1.0 & 4.2 & 1.0 & 1441 & 10.0 & 1.0 \\
\hline Rural & 5259 & 17.9 & $1.2(1.0 \text { to } 1.4)^{*}$ & 3.1 & $0.7(0.6$ to 1.0$)$ & 993 & 6.7 & $0.6(0.4$ to 1.2$)$ \\
\hline \multicolumn{9}{|l|}{ Medical insurance } \\
\hline Yes & 2349 & 17.1 & 1.0 & 6.3 & 1.0 & 463 & 14.4 & 1.0 \\
\hline No & 11425 & 16.1 & $0.9(0.7$ to 1.2$)$ & 3.3 & $0.5(0.4 \text { to } 0.7)^{*}$ & 1959 & 7.3 & $0.5(0.3 \text { to } 0.9)^{*}$ \\
\hline \multicolumn{9}{|l|}{ Domestic fuel } \\
\hline Non-smoky & 9421 & 15.7 & 1.0 & 4.2 & 1.0 & 1623 & 11.0 & 1.0 \\
\hline Smoky & 4405 & 17.5 & $1.1(1.0 \text { to } 1.3)^{*}$ & 3.0 & $0.7(0.5 \text { to } 0.9)^{*}$ & 810 & 3.9 & $0.3(0.2 \text { to } 0.5)^{*}$ \\
\hline \multicolumn{9}{|c|}{ Occupational exposures } \\
\hline Never $>1$ year & 11400 & 14.4 & 1.0 & 3.0 & 1.0 & 1763 & 6.6 & 1.0 \\
\hline Ever $>1$ year & 2426 & 25.3 & $2.0(1.8 \text { to } 2.3)^{*}$ & 7.3 & $2.5(2.0 \text { to } 3.1)^{*}$ & 670 & 14.0 & $2.3(1.6 \text { to } 3.3)^{*}$ \\
\hline \multicolumn{9}{|l|}{ Smoking } \\
\hline Never & 9051 & 14.0 & 1.0 & 3.1 & 1.0 & 1361 & 8.0 & 1.0 \\
\hline Light $(1-14) \dagger$ & 2365 & 18.3 & $1.4(1.2 \text { to } 1.6)^{*}$ & 4.2 & $1.4(1.0 \text { to } 1.8)^{*}$ & 462 & 6.9 & $0.9(0.5$ to 1.4$)$ \\
\hline Heavy $(15+) \dagger$ & 684 & 24.7 & $2.0(1.6 \text { to } 2.6)^{*}$ & 7.4 & $2.5(1.6 \text { to } 3.8)^{*}$ & 187 & 15.8 & $2.2(1.1 \text { to } 4.3)^{*}$ \\
\hline Ex-smoker & 1485 & 22.5 & $1.8(1.5 \text { to } 2.1)^{*}$ & 5.7 & $1.9(1.4 \text { to } 2.5)^{*}$ & 368 & 9.7 & $1.2(0.8$ to 2.0$)$ \\
\hline Non-cigaretteł & 224 & 21.7 & $1.7(1.2 \text { to } 2.5)^{*}$ & 3.2 & $1.0(0.5$ to 2.0$)$ & 51 & 9.2 & $1.2(0.4$ to 3.5$)$ \\
\hline \multicolumn{9}{|l|}{ Tuberculosis } \\
\hline Never & 13501 & 15.7 & 1.0 & 3.7 & 1.0 & 2287 & 8.6 & 1.0 \\
\hline Ever & 325 & 42.5 & $4.0(3.0 \text { to } 5.2)^{*}$ & 8.9 & $2.6(1.8 \text { to } 3.7)^{*}$ & 147 & 9.5 & $1.1(0.6$ to 2.1$)$ \\
\hline \multicolumn{9}{|l|}{ Body mass index } \\
\hline Obese & 2646 & 19.5 & $1.4(1.2 \text { to } 1.6)^{*}$ & 4.3 & $1.2(0.9$ to 1.6$)$ & 558 & 9.6 & $1.4(0.9$ to 2.2$)$ \\
\hline Overweight & 3144 & 16.2 & $1.1(1.0 \text { to } 1.3)^{*}$ & 4.0 & $1.1(0.8$ to 1.5$)$ & 542 & 9.4 & $1.4(0.8$ to 2.4$)$ \\
\hline Normal & 6158 & 14.7 & 1.0 & 3.6 & 1.0 & 995 & 7.1 & 1.0 \\
\hline Underweight & 1141 & 17.6 & $1.2(1.1 \text { to } 1.5)^{*}$ & 3.7 & $1.0(0.7$ to 1.5$)$ & 208 & 11.2 & 1.7 (0.9 to 3.2$)$ \\
\hline
\end{tabular}

$\mathrm{N}$, Weighted counts; first column applies to recent wheeze and asthma diagnosis

${ }^{*} \mathrm{p}<0.05$ for difference from reference stratum.

†Current daily and occasional manufactured and hand rolled cigarettes.

¥Current daily and occasional pipes, cigars, cheroots, cigarillos.

The main limitation of this study was that, because of the cross sectional design, respondents with symptoms or a diagnosis of asthma may have been more likely to report what they perceived as causal occupational exposures than respondents without symptoms. Differential recall bias is less likely to affect tuberculosis history as diagnosed tuberculosis is a specific event entailing a prolonged period of treatment. Some validation of the self-reported respiratory outcomes was obtained through PEFR measurements, which showed a clear separation of the means of those with and without wheeze and asthma diagnosis. With regard to asthma treatment, a strength of the study was the confirmation by the interviewer of the presence of medication in the home.

\section{Prevalence}

For purposes of international comparison with countries using the ECRHS questions, the age range 20-44 years is of interest. The prevalence of an asthma diagnosis in this age group was $2.7 \%$ in men and $3.1 \%$ in women, which is at the low end of the ECRHS range for developed countries, ${ }^{3}$ although it should be noted that the current study used a national rather than a city or regional sample. Among developing countries, the South African values were comparable to those of urban Mumbai, India $(3.8 \%$ in men, 3.1\% in women $)^{3}$ and higher than rates of self-reported asthma in rural Beijing $\left(<1 \%\right.$ in men and women). ${ }^{5}$ Current asthma medication use in this younger age group ( $1.1 \%$ in men, $1.0 \%$ in women) was lower than in all but one centre in the ECRHS studies cited. ${ }^{3}{ }^{17}$

The figures for recent wheeze in respondents aged $20-44$ years ( $11.7 \%$ in men, $14.5 \%$ in women, $13.4 \%$ overall) also lie at the lower end of the ECRHS range but are considerably higher than those recorded for Mumbai, Algiers, ${ }^{3}$ or rural Beijing. ${ }^{5}$ Accordingly, the prevalence ratio 


\begin{tabular}{|c|c|c|c|c|c|c|}
\hline & \multicolumn{2}{|c|}{$\begin{array}{l}\text { Recent wheeze } \\
(\mathrm{N}=13 \text { 002) }\end{array}$} & \multicolumn{2}{|c|}{$\begin{array}{l}\text { Asthma diagnosis } \\
(\mathrm{N}=13 \text { 002) }\end{array}$} & \multicolumn{2}{|c|}{$\begin{array}{l}\text { Asthma medication use } \\
(\mathrm{N}=2219)\end{array}$} \\
\hline & OR & $95 \% \mathrm{Cl}$ & OR & $95 \% \mathrm{Cl}$ & OR & $95 \% \mathrm{Cl}$ \\
\hline Women & $1.6^{*}$ & 1.3 to $1.8^{* *}$ & 1.2 & 0.9 to 1.6 & $0.6^{*}$ & 0.4 to $0.9^{* *}$ \\
\hline \multicolumn{7}{|l|}{ Age (years) } \\
\hline 15-24 & 1.0 & & 1.0 & & 1.0 & \\
\hline $25-44$ & 0.9 & 0.7 to 1.1 & 0.7 & 0.5 to 1.0 & 1.2 & 0.5 to 2.7 \\
\hline$>44$ & $1.3^{*}$ & 1.0 to 1.6 & $1.0^{*}$ & 0.7 to 1.5 & $2.3^{*}$ & 1.0 to 5.7 \\
\hline \multicolumn{7}{|l|}{ Asset index } \\
\hline I (poorest) & 1.0 & & 1.0 & & 1.0 & \\
\hline$\|$ & 1.1 & 0.9 to 1.3 & 0.9 & 0.6 to 1.3 & 2.0 & 1.0 to 4.1 \\
\hline III & 0.8 & 0.6 to $1.0^{* *}$ & 0.7 & 0.5 to 1.2 & 1.7 & 0.8 to 3.8 \\
\hline IV & 1.0 & 0.7 to 1.3 & 0.9 & 0.5 to 1.5 & 2.7 & 1.1 to $6.5^{* *}$ \\
\hline V & 0.9 & 0.7 to 1.3 & 0.9 & 0.5 to 1.6 & 2.3 & 0.8 to 6.4 \\
\hline \multicolumn{7}{|l|}{ Education (years) } \\
\hline None & 1.0 & & 1.0 & & 1.0 & \\
\hline $1-7$ & 0.8 & 0.6 to $0.9^{* *}$ & 1.0 & 0.7 to 1.4 & 1.4 & 0.8 to 2.6 \\
\hline $8-12$ & 0.5 & 0.4 to $0.7^{* *}$ & 0.5 & 0.3 to $0.8^{* *}$ & 0.8 & 0.4 to 1.6 \\
\hline$>12$ & $0.4^{*}$ & 0.3 to $0.6^{* *}$ & $0.6^{*}$ & 0.4 to 1.1 & 0.6 & 0.2 to 1.8 \\
\hline \multicolumn{7}{|l|}{ Racial group } \\
\hline African & 1.0 & & 1.0 & & 1.0 & \\
\hline Coloured & 0.8 & 0.6 to $1.0^{* *}$ & 1.3 & 0.9 to 1.9 & 3.3 & 1.9 to $5.7^{* *}$ \\
\hline White & 1.7 & 1.2 to $2.6^{* *}$ & 2.1 & 1.2 to $3.7^{* *}$ & 1.4 & 0.5 to 3.9 \\
\hline Asian & $1.4^{*}$ & 1.0 to 1.9 & 1.7 & 0.9 to 3.0 & $2.5^{\star}$ & 1.0 to $6.3^{* *}$ \\
\hline Rural residence & 1.1 & 0.8 to 1.6 & 0.9 & 0.6 to 1.4 & 1.4 & 0.7 to 2.7 \\
\hline No medical insurance & 1.0 & 0.8 to 1.2 & $0.7^{*}$ & 0.5 to $1.0^{* *}$ & 0.6 & 0.3 to 1.2 \\
\hline Smoky domestic fuel & 0.9 & 0.8 to 1.2 & 0.8 & 0.5 to 1.1 & $0.5^{\star}$ & 0.3 to $0.8^{* *}$ \\
\hline Occupational exposure & $1.8^{*}$ & 1.5 to $2.0^{* *}$ & $1.9^{*}$ & 1.4 to $2.4^{* *}$ & 1.5 & 1.0 to 2.2 \\
\hline \multicolumn{7}{|l|}{ Smoking } \\
\hline Non-smoker & 1.0 & & 1.0 & & 1.0 & \\
\hline Light (1-14)† & 1.5 & 1.3 to $1.9^{* *}$ & 1.2 & 0.9 to 1.7 & 0.5 & 0.3 to $0.8^{* *}$ \\
\hline Heavy $(15+) \dagger$ & 1.8 & 1.4 to $2.4^{\star *}$ & 1.5 & 0.9 to 2.4 & 0.8 & 0.4 to 1.8 \\
\hline Ex-smokers & 1.3 & 1.1 to $1.6^{* *}$ & 1.2 & 0.9 to 1.8 & 0.8 & 0.4 to 1.3 \\
\hline Non-cigaretteł & $1.6^{*}$ & 1.0 to $2.5^{* *}$ & 0.8 & 0.4 to 1.7 & 0.4 & 0.1 to 1.3 \\
\hline Tuberculosis (ever) & $3.4^{*}$ & 2.5 to $4.7^{* *}$ & $2.2^{*}$ & 1.5 to $3.2^{* *}$ & 1.0 & 0.5 to 2.0 \\
\hline \multicolumn{7}{|l|}{ Body mass index } \\
\hline Normal & 1.0 & & 1.0 & & 1.0 & \\
\hline Obese & 1.2 & 1.0 to $1.4^{* *}$ & 1.0 & 0.8 to 1.3 & 1.1 & 0.7 to 1.9 \\
\hline Overweight & 1.0 & 0.9 to 1.2 & 1.0 & 0.7 to 1.3 & 1.2 & 0.7 to 1.9 \\
\hline Underweight & 1.1 & 0.9 to 1.4 & 1.0 & 0.7 to 1.4 & 1.5 & 0.8 to 2.7 \\
\hline
\end{tabular}

$\mathrm{N}$, number of observations; records with missing values excluded from analysis. ${ }^{*} p<0.05$ (Wald test) for overall significance of variable in the model.

${ }_{* *}^{*} \mathrm{p}<0.05$ ( $t$ test) for stratum difference from reference stratum.

tCurrent daily and occasional manufactured and hand rolled cigarettes. ‡Current daily and occasional pipes, cigars, cheroots, cigarillos.

of asthma diagnosis (and treatment) to recent wheeze was lower than that found in other surveys in developing countries.

\section{Sociodemographic predictors}

Whereas women reported a higher prevalence of wheezing at all ages, men aged 15-19 years and those $>44$ years reported higher prevalences of asthma diagnosis than women (results not shown). Men were also more likely to use asthma medication than women at all ages. Possible sex linked selection bias has been mentioned. However, the results are also compatible with a sex bias in treatment in favour of men and, at certain ages, in diagnosis.

The associations of markers of socioeconomic status with the outcome differed somewhat between wheezing and asthma diagnosis. Wheezing showed a strong inverse association with education level. A similar "protective" effect of education has been noted for chronic bronchitis in Brazill ${ }^{18}$ and for obstructive lung disease and spirometric airflow limitation in Norway. ${ }^{19}$ The mechanism of this beneficial effect of education is unclear since smoking, occupational and household exposures were included in the analysis in

Table 4 Population attributable fraction for recent wheeze and asthma diagnosis of past tuberculosis, occupational exposure and current smoking $(N=13$ 826)

\begin{tabular}{|c|c|c|c|c|c|}
\hline & \multirow[b]{2}{*}{ p (\%) } & \multicolumn{2}{|c|}{ Recent wheeze } & \multicolumn{2}{|c|}{ Asthma ever } \\
\hline & & POR & PAF (\%) & POR & PAF (\%) \\
\hline Tuberculosis (ever) & 2.4 & 3.4 & 5.4 & 2.2 & 2.7 \\
\hline Occupational exposure & 17.5 & 1.8 & 12.2 & 1.9 & 13.6 \\
\hline Light smoking (1-14/day) & 17.1 & 1.5 & 7.8 & - & - \\
\hline Heavy smoking (15+/day) & 4.9 & 1.8 & 3.7 & - & - \\
\hline Obesity & 20.2 & 1.2 & 3.8 & - & - \\
\hline
\end{tabular}

p, population prevalence of exposure; POR, prevalence odds ratio (fully adjusted, table 3); PAF, population attributable fraction. 
addition to urban status, racial group, and asset index. The inverse association with education is also in contrast to the lack of an association with asset index and to the higher prevalence of wheeze among whites and Asians who, on average, have a higher standard of living than Africans. ${ }^{20}$

This effect of education may be partly explained by cultural or linguistic differences in response to symptom questions. Some variation in the sensitivity and specificity of asthma symptoms for bronchial hyperresponsiveness has been shown across European countries, which may reflect linguistic differences. ${ }^{21}$ Linguistic influences on responses may be amplified where there is a very wide gap in education within a population, as in this survey. Another possible explanation is that, since occupational exposure was measured only as a dichotomous variable in this study, lack of education may act as a proxy for the degree of occupational exposure. For example, respondents with little or no education are more likely to work in the dustiest unskilled jobs than better educated subjects.

Access to medical care would be expected to have a greater role in reported asthma diagnosis and treatment than in reported symptoms. The prevalence of an asthma diagnosis remained lower among Africans and was associated with having medical insurance, while the ratio of asthma diagnosis to wheeze (from table 2) was lowest among the poorest, those with least education, and among Africans. These associations are consistent with an effect of access to medical care. Among respondents with wheezing or an asthma diagnosis, asset index had a particularly strong association with treatment. A large gap in access to respiratory medicine expertise between the wealthier and poorer regions in South Africa has been documented, ${ }^{22}$ reflecting social class and regional disparities in medical care in general. ${ }^{23}$

\section{Environmental and medical predictors}

Occupational exposure and, surprisingly, a past history of tuberculosis were consistent predictors of wheezing and asthma diagnosis. Although not shown, these factors showed robust associations with all of the wheeze symptoms elicited in the study including wheezing with breathlessness, wheezing not only with a cold, and disturbance by night wheeze. Obesity was associated with recent wheeze, but only among younger women. The specificity of this association to women has been noted in some, ${ }^{12}{ }^{13}$ but not all, ${ }^{14}$ previous studies. As obesity was so common in this population, overall the PAF $(3.8 \%)$ was close to that for heavy smoking.

There are now a number of population studies of adult asthma and asthma symptoms which show an association with occupational exposures (reviewed by the American Thoracic Society ${ }^{24}$ ). This includes studies such as the current one in which exposure to smoke, dust, or fumes was selfreported. The PAFs of occupational exposure in respect of an asthma diagnosis and wheezing in this study $(12.2 \%$ and $13.6 \%$, respectively) are close to the median value of $15 \%$ derived in the abovementioned review. ${ }^{24}$ The PAF of $12.2 \%$ of occupational exposure for wheeze in fact exceeded the combined PAF of light and heavy current smoking (11.5\%) in this study.

The ability of a history of tuberculosis to predict wheezing and an asthma diagnosis in a national population study is interesting. Airways obstruction is a well documented long term sequel of tuberculosis..$^{25}$ The association of past tuberculosis with wheezing would therefore be expected. In a case-control study of miners Churchyard $e t a^{27}$ found an odds ratio of 2.3 (95\% CI 1.3 to 4.1 ) for wheezing and previous tuberculosis, controlling for age, smoking, silicosis and duration of employment.
The association of past tuberculosis with an asthma diagnosis is difficult to explain. Although the cross sectional design of our study cannot establish the direction of the effect, if the effect is real it means that an asthma diagnosis is more likely to be a consequence of previous tuberculosis than the converse. One possible explanation is misdiagnosis of airflow obstruction as asthma in those with chronic post tuberculous lung disease. The pathogenesis of post tuberculosis airways obstruction is speculative. Willcox and Ferguson, reporting a positive association between the extent of radiological disease at presentation, subsequent loss of forced expiratory volume in l second, and sputum production, suggested a major role for chronic obstructive bronchitis, probably with bronchiectasis. ${ }^{25}$ However, there do not appear to be data on whether post tuberculous airways obstruction is characterised by reversible airflow obstruction or non-specific airways hyperresponsiveness which might lead to a diagnosis of asthma. An alternative explanation for the association is that "asthma" medications prescribed for symptoms of airflow limitation come to be associated with an asthma diagnosis in the mind of the respondent. Current guidelines for the treatment of chronic obstructive pulmonary disease (COPD) in South Africa include recommendations for the selective use of bronchodilators and glucocorticosteroids. ${ }^{28}$

The findings may also reflect the difficulty, in an adult survey in this setting, of distinguishing asthma from COPD due to smoking and occupational exposures. In a UK community survey Burney et $a l^{29}$ found that smoking was a stronger predictor of non-specific bronchial hyperresponsiveness at an older age ( $>40$ years) than was atopy. In the current study, differential responses to symptom and diagnosis questions by language and education, disparities in access to medical care, and increasing use of asthma medication for both asthma and COPD may all have contributed to a lack of specificity in the wheezing question as well as the asthma diagnosis question. The finding of very similar associations with regard to chronic bronchitis in a companion analysis ${ }^{8}$ as were found for asthma in this study support this interpretation. Further studies using spirometry and tests of non-specific bronchial hyperresponsiveness would help to distinguish between the two conditions. In addition, research is needed into possible variations in validity and reliability of standard symptom questions by language, education, and other social variables in this population.

The results reinforce the earlier conclusion with regard to chronic bronchitis ${ }^{8}$ that control of hazardous occupational exposures merits equal attention to the more visible tobacco control activities in the public health strategy of the country. There is also a case for greater recognition within the health services of post tuberculous obstructive lung disease. This condition does not seem to meet the definition of COPD proposed by the National Heart, Lung, and Blood Institute and World Health Organisation Global Initiative for Chronic Obstructive Lung Disease (GOLD) which characterises the air flow limitation of COPD as "usually ... associated with an abnormal inflammatory response of the lungs to noxious particles or gases". ${ }^{30}$ Further pathophysiological research is required to better characterise the mechanisms involved in post tuberculous airways obstruction and the therapeutic implications, if any.

\section{ACKNOWLEDGEMENTS}

The National Department of Health was the initiator and main funder of the study, the South African Medical Research Council served as coordinator and funder, while the Centre for Health Systems Research and Development conducted the fieldwork. Macro International provided technical assistance and USAID additional funding. The provincial health departments each made a coordinator 
available. The Human Sciences Research Council monitored the fieldwork quality. Statistics South Africa provided the sampling frame and sample details. This collective effort involved a large number of dedicated people who are gratefully acknowledged. Desiree Pieterse and Elize De Kock expended considerable effort in producing tables for this article.

\section{Authors' affiliations}

R I Ehrlich, School of Public Health and Family Medicine, University of Cape Town, South Africa

N White, UCT Lung Institute, Cape Town, South Africa

R Norman, D Bradshaw, Burden of Disease Research Unit, South African Medical Research Council, Cape Town, South Africa

R Laubscher, C Lombard, Biostatistics Unit, South African Medical Research Council, Cape Town, South Africa

K Steyn, Chronic Diseases of Lifestyle Research Unit, South African Medical Research Council, Cape Town, South Africa

Competing interests: none declared

Dedicated to the memory of Neil Walton White, 1954-2004.

\section{APPENDIX 1 QUESTION WORDING AND VARIABLE DEFINITIONS}

Asthma symptoms: (1) "During the last year have you had wheezing or tightness of your chest? If yes, were you also short of breath?" (2) "Do you only get wheezing when you have a cold?" (3) "Is your sleep every interrupted by wheezing or a tight chest?"

Asthma diagnosis: "Have you ever been told by a doctor, nurse or other health care worker that you have ... asthma?"

Asthma treatment (to interviewer): “... ask the respondent to show you all the medication taken every day during the last month"

Body mass index: underweight $<18.5 \mathrm{~kg} / \mathrm{m}^{2}$; reference $18.5-$ $24.9 \mathrm{~kg} / \mathrm{m}^{2}$; overweight $25-29.9 \mathrm{~kg} / \mathrm{m}^{2}$; obese $\geqslant 30 \mathrm{~kg} / \mathrm{m}^{2}$.

Occupational exposure: "(Have you) ever worked in a job ... regularly exposed to smoke, dust, fumes or strong smells (for $>$ l year)" or "... ever worked underground in a mine".

Smoky domestic exposure: "... coal, wood or animal dung for cooking or heating" versus "... gas, paraffin or electricity" (mixed use with electricity or paraffin was included in the latter group).

Rural v urban residence: This was based on a categorisation of areas by the national statistical office on the basis of the level of organised service provision. Rural areas in South Africa include prosperous commercial farming areas but most of the rural population live in poverty stricken subsistence sectors.

Population attributable fraction: $\mathrm{p}(\mathrm{POR}-1) /[\mathrm{p}(\mathrm{POR}-1)+1]$ where $\mathrm{POR}=$ prevalence odds ratio as an estimate of the relative risk and $\mathrm{p}=$ prevalence of the risk factor in the population. ${ }^{16}$

\section{REFERENCES}

1 Anonymous. Variations in the prevalence of respiratory symptoms, selfreported asthma attacks, and use of asthma medication in the European Community Respiratory Health Survey (ECRHS). Eur Respir J 1996;9:687-95.

2 Janson C, Anto J, Burney P, et al. The European Community Respiratory Health Survey: what are the main results so far? Eur Respir J 2001;18:598-611.

3 Chowgule RV, Shetye VM, Parmar JR, et al. Prevalence of respiratory symptoms, bronchial hyperreactivity, and asthma in a megacity: results of the
European Community Respiratory Health Survey in Mumbai (Bombay). Am J Respir Crit Care Med 1998;158:547-54

4 Priftanji AV, Qirko E, Layzell JCM, et al. Asthma and allergy in Albania. Allergy 1999;54:104-7.

5 Chan-Yeung $M$, Zhang L-X, Tu D-H, et al. The prevalence of asthma and asthma-like symptoms among adults in rural Beijing, China. Eur Respir $J$ 2002; 19:853-8.

6 Saraclar Y, Cetinkaya F, Tuncer A, et al. The prevalence of self-reported asthma and respiratory symptoms in Ankara, Turkey. Respir Med 1997:91:461-3.

7 Bradshaw D, Schneider M, Dorrington RE, et al. South African cause of death profile in transition: 1996 and future trends. S Afr Med J 2002;92:618-23.

8 Ehrlich RI, White N, Norman R, et al. Predictors of chronic bronchitis in South African adults. Int J Tuberc Lung Dis 2004;8:369-76.

9 Department of Health of the Republic of South Africa, South African Medical Research Council, Macro International. South African demographic and health survey 1998. Pretoria: Department of Health of the Republic of South Africa, 2001:1-338.

10 Booysen F. LeR. Using demographic and health surveys to measure povertyan application to South Africa. J Stud Economics Econometrics 2002;26:53-70.

11 Filmer D, Pritchett L. Estimating wealth effects without expenditure data-or tears: an application to educational enrollments in states of India, World Bank Policy Research Working Paper. Washington, DC: Development Economics Research Group, World Bank, 1998.

12 Chen Y, Dales R, Tang M, et al. Obesity may increase the incidence of asthma in women but not in men: longitudinal observations from the Canadian National Population Health Surveys. Am J Epidemiol 2002;155:198-202.

13 Shaheen SO, Sterne JAC, Montgomery SM, et al. Birth weight, body mass index and asthma in young adults. Thorax 1999;54:396-402.

14 Luder E, Ehrlich RI, Lou WYW, et al. The association between asthma and body mass in adults. Respir Med 2004;98:29-37.

15 Breiman L, Freidman JH, Olshen RA, et al. Classification and regression trees. Belmont, California: Wadsworth International Group, 1984.

16 Kahn HA, Sempos CT. Statistical methods in epidemiology. New York: Oxford University Press, 1989:74-5.

17 Janson C, Chinn S, Jarvis D, et al. Physician-diagnosed asthma and drug utilization in the European Community Respiratory Health Survey. Eur Respir J 1997; 10:1795-802.

18 Menezes AMB, Victora CG, Rigatto M. Prevalence and risk factors for chronic bronchitis in Pelotas, RS, Brazil: a population-based study. Thorax 1994:49:1217-21.

19 Bakke PS, Hanoa R, Gulsvik A. Educational level and obstructive lung disease given smoking habits and occupational airborne exposure: a Norwegian community study. Am J Epidemiol 1995;141:1080-8.

20 Myer L, Ehrlich RI, Susser E. Social epidemiology in South Africa. Epidemiol Rev 2004; 26:112-23.

21 Burney PGJ, Laitinen LA, Perdrizet S, et al. Validity and repeatability of IUATLD (1984) bronchial symptoms questionnaire: an international comparison. Eur Respir J 1989;2:940-5.

22 White NW, Girdler-Brown BV, Feldman C, et al. Respiratory illness and pulmonology in South Africa-distribution and trends 1987-1997. S Afr Respir J 2001;7:137-43

23 Day C, Gray D. Health and related indicators. In: ljumba P, Ntuli A, Barron P, eds. South African Health Review. Johannesburg: Health Systems Trust, 2002:451-510.

24 American Thoracic Society. Occupational contribution to the burden of airway disease. Am J Respir Crit Care Med 2003;167:787-97.

25 Willcox PA, Ferguson D. Chronic obstructive airways disease following treated pulmonary tuberculosis. Respir Med 1989;83:195-8.

26 Hnizdo E, Singh T, Churchyard GJ. Chronic pulmonary function impairment caused by initial and recurrent pulmonary tuberculosis following treatment. Thorax 2000;55:32-8.

27 Churchyard GJ, Hnizdo E, White N. Pulmonary tuberculosis in relation to lung function loss. Safety in Mines Research Advisory Committee (SIMRAC) Research Report: Health 617. Johannesburg: SIMRAC, 2001.

28 Working Group of the South African Pulmonology Society. Guidelines for the management of chronic obstructive lung disease. S Afr Med J 1998:88:999-1010.

29 Burney PGJ, Britton JR, Chinn S, et al. Descriptive epidemiology of bronchial reactivity in an adult population: results from a community study. Thorax 1987;42:38-44.

30 Pauwels RA, Buist S, Calverley PMA, on behalf of the GOLD Scientific Committee, et al. Global strategy for the diagnosis, management and prevention of chronic obstructive pulmonary disease: NHLBI Global Initiative for Chronic Obstructive Lung Disease (GOLD) Workshop Summary. Am J Respir Crit Care Med 2001;163:1256-76. 